\title{
IDENTIFIKASI DAN ISOLASI ISOLAT NON POLAR, SEMIPOLAR DAN NON POLAR DARI FRAKSI HEKSANA EKSTRAK ETANOL DAUN SIRIH (Piper betle L.) DENGAN METODE TLC SCANNER DAN $G C-M S$
}

\author{
Ahwan \\ Program Studi Farmasi, Fakultas Sains dan Teknologi, Universitas Sahid Surakarta \\ email : ahone.far02@gmail.com
}

\begin{abstract}
ABSTRAK
Tanaman daun sirih (piper betlle L.) merupakan tanaman yang banyak digunakan pada jaman nenek moyang dulu sebagai campuran inang, sabun, dan bumbu masakan. Daun sirih tersebut banyak mengandung metabolik sekunder yang mempunyai aktifitas sebagai obat. Dalam daun sirih mengandung komponen senyawa kimia yang dapat diisolasi dan mempunyai efek atau aktifitas tertentu terhadap pengobatan (antikanker, antimikroba dan radikal bebas). Penelitian ini menerangkan isolat yang mempunyai struktur kimia yang bertanggungjawab terhadap aktifitasnya dengan cara proses ekstraksi (maserasi), fraksinasi (kromatografi cair vakum), identifikasi (KLT preparatif, densitometry dan GC-MS). Hasil yang diperoleh berupa isolat non polar, semipolar dan polar dari fraksi heksana. Isolat tersebut di identifikasi dengan KLT, TLC scanner dan GC-MS. Hasil yang diperoleh isolat nonpolar: Alkana (9,43\%); alkohol $(1,34)$; asam karboksilat $(2,57)$; turunan fenol $(32,09)$; furan $(0,16)$ dan terpena $(2,21)$, Isolat semipolar: alkana $(7,77)$; alkohol $(1,25)$; aldehide $(2,88)$; turunan fenol $(31,96)$; furan $(0,26)$ dan terpena $(0,64)$ sedangkan isolat polar: alkana (10.03); alkohol (2,73); asam karboksilat $(14,10)$; benzopiren $(30,73)$; turunan fenol $(26,32)$ dan organo sulfur $(4,20)$. Senyawa yang mempunyai aktifitas adalah komponen fenol; kavikol, eugenol (non polar dan semipolar); cinamomil klorida (polar) dan senyawa terpena: geraniol, citronella propionate (non polar); cis-pinene (semipolar).
\end{abstract}

Kata Kunci: Piper betle L., fraksi $n$-heksana, nonpolar, semi polar, polar, analisis GC-MS

\begin{abstract}
Betel leaf plants (piper betlle L.) is a plant widely used in ancient times as a mixture of host, soap, and seasoning. Betel leaf contains a lot of secondary metabolics that have the activity as a drug. In betel leaf contains components of chemical compounds that can be isolated and have certain effects or activities on treatment (anticancer, antimicrobial and free radicals). This study describes isolates that have chemical structures responsible for their activity by extraction (maceration), fractionation (vacuum liquid chromatography), identification (preparative TLC, densitometry and GC-MS). The results obtained are non polar, semi polar and polar isolates of the hexane fraction. The isolates were identified with TLC, TLC scanner and GC-MS. Results obtained by non polar isolates: Alkenes (9.43\%); alcohol (1.34); carboxylic acid (2.57); phenol derivatives (32.09); furan (0.16) and terpene (2.21), semi polar isolate: alkenes $(7,77)$; alcohol $(1,25)$; aldehyde $(2.88)$; phenol derivatives (31.96); furan (0.26) and terpene (0.64) while polar isolates: alkenes (10.03); alcohol (2.73); carboxylic acid $(14,10)$; benzopyren $(30.73)$; phenol derivatives $(26,32)$ and organo sulfur (4.20). The compound having activity is a phenol component; chavicol, eugenol (non polar and semi polar); cinnamoyl chloride (polar) and terpene compounds: geraniol, citronella propionate (non polar); cis-pinene (semi polar).
\end{abstract}

Keywords: Piper betle L., n-hexane fraction, non polar, semi polar, polar, GC-MS analysis 


\section{PENDAHULUAN}

Pemanfaatan bahan alam sebagai obat tradisional di Indonesia akhir-akhir ini meningkat, bahkan beberapa bahan alam telah diproduksi secara fabrikasi dalam skala besar. Penggunaan obat tradisional dinilai memiliki efek samping yang lebih kecil dibandingkan dengan obat yang berasal dari bahan kimia, di samping itu harganya lebih terjangkau (Tampubolon, 1981).

Keuntungan tersebut di atas, obat tradisional terdapat dalam jumlah yang banyak di Indonesia. Selanjutnya senyawa aktif yang terkandung di dalam obat tradisional dapat dijadikan sebagai senyawa penuntun (Sardjoko, 1993).

Salah satu tanaman yang dapat dimanfaatkan sebagai obat adalah tumbuhan Piper betle yang dikenal dengan sirih. Masyarakat memanfaatkan tumbuhan ini.

Untuk tujuan pengobatan pada hidung berdarah (mimisen-Jawa), mulut berbau, mata sakit, radang tenggorokan (Sudarsono dkk., 1996). Selain itu sirih juga berkhasiat sebagai antisariawan, antibatuk, astringent, dan antiseptik (Anonim, 1980). Kandungan kimia tumbuhan sirih adalah saponin, flavonoid, polifenol, dan minyak atsiri (Anonim, 2000).

Keuntungan lain penggunaan obat tradisional adalah bahan bakunya mudah diperoleh dan harganya yang relatif murah. Delapan puluh persen penduduk Indonesia hidup di pedesaan dan kadang sulit dijangkau oleh tim medis dan obat-obat modern
(Poedjarwoto dkk., 1992). Mahalnya biaya pengobatan modern menyebabkan masyarakat kebanyakan berpaling ke obat tradisional yang berasal dari alam.

\section{METODE PENELITIAN}

\subsection{Alat dan Bahan}

Alat yang digunakan dalam penelitian ini adalah seperangkat alat maserasi, evaporator, alat-alat gelas, pipet ukur, mikropipet, mikro syringe, rak tabung, propipet, pipet ukur, yellow tips, blue tips, bejana kromatografi, flakon, perangkat alat kromatografi cair vakum, mikropipet, pipa penyemprot, oven, lampu UV $254 \mathrm{~nm}$ dan 366 nm TLC Scanner C9310 Shimadzu dan kromatografi gas QP MS 2010 S.

Bahan yang digunakan adalah simplisia daun sirih (Piper betle L.), etanol, slika gel 60 $\mathrm{F}_{254}$, asam formiat, kloroform, etil asetat dan toluene.

\subsection{Jalannya Penelitian}

\subsubsection{Determinasi Tanaman}

Determinasi dilakukan di Laboratorium Taksonomi Tumbuhan Fakultas Biologi Universitas Gadjah Mada Yogyakarta.

\subsubsection{Pengumpulan dan Penyiapan Bahan}

Bahan daun sirih (Piper betle L.), diperoleh dari Palur, Kabupaten Karanganyar, Jawa Tengah. Daun sirih (Piper betle L.),

Jenis Kolom : Rxi 1ms

Suhu Kolom : 50 0C

Suhu Injektor : 280 0C

Tipe Injektor : Splitless

Waktu alir gas : $1.16 \mathrm{~mL} / \mathrm{min}$ 
Identifikasi dan Isolasi Isolat....

Split ratio $\quad: 1.0$ diblender untuk mendapatkan serbuk daun ibersihkan dari kotoran dengan dicuci air, sirih (Piper betle L.), setelah itu diiris tipis, dikeringkan dan

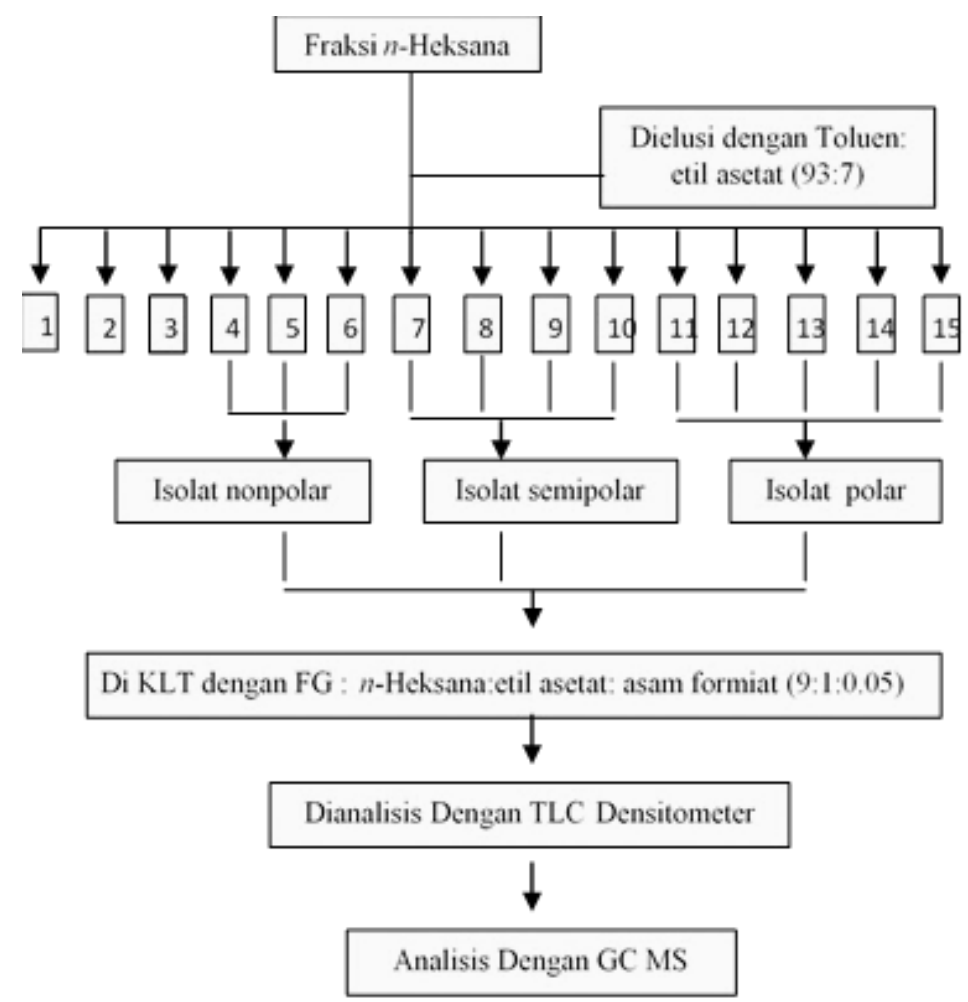

Gambar 1. Mekanisme Pemisahan Fraksi dengan KVC (Kromatografi Vakum Cair

\subsubsection{Penyarian}

Metode penyarian yang digunakan adalah maserasi. Simplisia daun sebanyak 2000 gram dimasukkan dalam $14000 \mathrm{~mL}$ etanol dalam wadah stainless, ditutup rapat dan didiamkan selama 24 jam sambil diadukaduk dan terlindung dari cahaya. Setelah 24 jam disaring dengan hingga didapatkan ampas dan filtrat etanol, kemudian dilakukan remaserasi sebanyak 2 kali yaitu ampas direndam lagi selama 24 jam dan diaduk sehingga didapatkan ampas dan filtrat etanol. Filtrat etanol yang didapat dicampur dan dipekatkan dengan menggunakan rotary evaporator, sehingga didapat ekstrak kental etanol daun sirih sebanyak 90 gram. Diambil
40 gram dilakukan fraksinasi menggunakan $n$-heksana dengan metode partisi. Dari hasil ini diperoleh tiga fraksi yaitu non polar, semipolar dan polar. Seluruh fraksi yang dihasilkan dideteksi dengan Kromatografi Lapis Tipis (KLT) menggunakan eluen gabungan toluene:etil asetat $=9: 1$ (Haryoto, 2007).

\subsubsection{Tahapan Isolasi}

Urutan proses isolasi dapat dilihat pada

\section{Gambar 1.}

\subsubsection{Pembacaan dengan Gas \\ Chromatography Massa Spectrum}

Isolat fraksi $n$-heksana polar dibaca menggunakan Gas Chromatography Shimadzu QP 2010S dengan menggunakan. 


\section{HASIL DAN PEMBAHASAN}

\subsection{Ekstraksi Daun Sirih}

Daun sirih dikeringkan di dalam oven pada suhu $60^{\circ} \mathrm{C}$ yang bertujuan agar suhu dapat diatur dan mencegah simplisia dari adanya kontaminan. Tujuan dari pengeringan adalah untuk mencegah timbulnya bakteri, jamur yang dapat menyebabkan perubahan komponen kimia simplisia pada saat dikemas dan bila disimpan dalam waktu yang lama kualitas simplisia dapat terjamin, disamping itu untuk menghilangkan kadar air yang terdapat dalam daun dan untuk keefektifan penyarian sehingga dalam proses ekstraksi bahan telah kering dan lebih mudah berinteraksi dengan cairan penyari.

Daun sirih yang telah kering dijadikan serbuk kasar dengan menggunakan blender, kemudian diayak agar diperoleh serbuk dengan ukuran yang sama sehingga proses penyarian akan maksimal. Penyerbukan bertujuan untuk memperluas permukaan simplisia sehingga proses ekstraksi semakin efektif dan efisien, karena dengan penyerbukan sejumlah besar dinding-dinding sel akan rusak atau pecah sehingga akan memudahkan masuknya cairan penyari ke dalam sel-sel yang kemudian terjadi perpindahan masa zat aktif dari dalam serbuk keluar atau ke dalam cairan penyari (Anonim, 1986).

Cairan penyari yang digunakan adalah etanol $96 \%$ yang merupakan campuran hidroalkohol yang kerjanya gabungan antara pelarut polar dan non polar, karena keduanya mudah bercampur dan memungkinkan kombinasi yang fleksibel untuk mengekstraksi bahan aktif (Ansel, 1989).

Campuran etanol dan air bertujuan untuk meningkatkan efektifitas penyarian. Kemudian cairan penyari akan menembus dinding sel dan masuk ke dalam rongga sel yang mengandung zat aktif sehingga zat aktif ikut larut dalam cairan penyari. Pada penyarian dengan maserasi perlu dilakukan pengadukan untuk meratakan konsentrasi larutan diluar butir serbuk simplisia, sehingga tetap terjaga derajat perbedaan konsentrasi yang sekecil-kecilnya antara larutan di dalam sel dengan larutan di luar sel (Anonim, 1986). Filtrat yang diperoleh diuapkan dengan vacuum rotary evaporator. Setelah diuapkan, hampir semua etanol menguap sehingga yang tertinggal sebagian besar adalah air. Hasil penguapan ini disebut ekstrak kental berair. Kandungan air dihilangkan dengan menguapkan ekstrak di atas waterbath dengan menjaga suhunya $<60^{\circ} \mathrm{C}$ agar kandungan zat aktif tanaman tetap stabil. Karena ekstrak daun sirih mengandung banyak minyak, maka ekstrak yang didapat adalah ekstrak agak kental. Ekstrak agak kental yang diperoleh kemudian ditimbang dan dihitung rendemennya. Hasil ekstrak etanol daun sirih (Piper betle L.) diperoleh rendemen sebesar $24,94 \%$. 


\subsection{Fraksinasi dan Isolasi Ektrak Etanol Daun Sirih}

Hasil Ekstrak etanol dipartisi dengan fraksi $n$-heksana dan hasil fraksi tersebut di Kromatografi vakum cair dengan eluen bertingkat dari non polar sampai ke polar. Hasil fraksi diKLT menggunakan fase gerak : toluene : etil asetat (9:1). Isolasi dilakukan bertingkat untuk memperoleh isolat yang mengandung senyawa yang terekstraksi sempurna berdasarkan sifat kepolarannya terhadap fase gerak (eluen) dan fase diam digunakan, sehingga akan tahu komponen apa saja yang cenderung mempunyai aktifitas senyawa dilihat dari analisis kualitatif (KLT preparatif, densitometry dan $G C-M S)$.

\subsection{Uji Dengan Kromatografi Lapis Tipis (KLT)}

Isolat yang diiperoleh dilakukan uji kualitatif untuk melihat profil kromatografi yang terjadi dengan perbedaan kepolaraan dan daya absorbsi antara fase diam dan solute (zat terlarut). Fase gerak yang digunakan adalah Toluen: etil asetat: asam formiat (93: 7: 0.05) dan fase diam silika gel $60^{\mathrm{F} 254}$. Hasil yang diperoleh (Gambar 2) pada sinar tampak atau visible terdapat pemisahan dengan 4 spot/bercak pada sampel/ekstrak dengan harga $\operatorname{Rf}(0,23 ; 0,30 ; 0,35$ dan 0,42$)$, isolat nonpolar terdapat 2 spot nilai $\operatorname{Rf}(0,25$ dan $0,37)$, isolat semipolar terdapat 3 spot nilai $\mathrm{Rf}$ $(0,2 ; 0,35 ; 0,37)$ sedangkan isolat polar terdapat 4 spot nilai $\operatorname{Rf}(0,23 ; 0,34 ; 0,37$ dan $0,40)$.

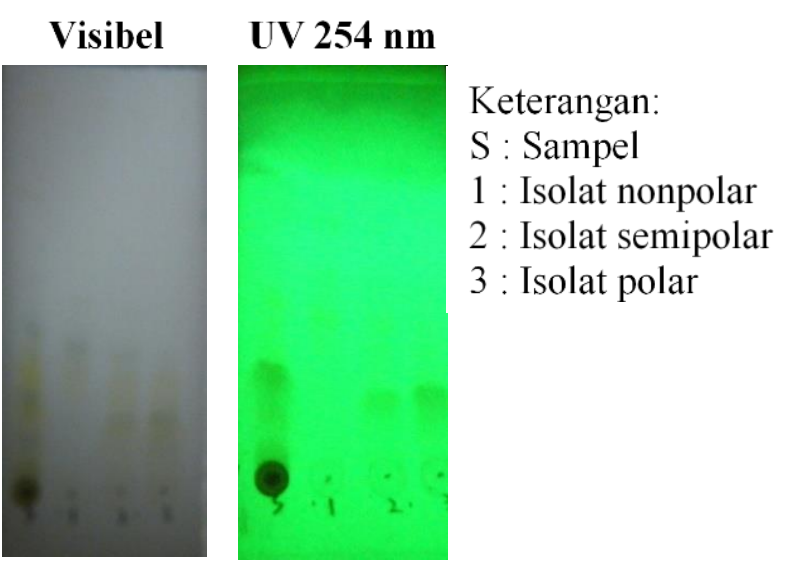

Gambar 2. Profil Kromatografi Lapis Tipis

\subsection{Analisis Kualitatif Profil KLT Densitometer}

Hasil tersebut dilanjutkan lagi dengan melakukan KLT densitometer dengan panjang gelombang $375 \mathrm{~nm}$ dimana panjang gelombang tersebut merupakan panjang gelombang optimum dari tiap bercak. Pada senyawa ekstrak etanol daun sirih mempunyai 7 (tujuh) peak dimana pertama yang mempunyai luas area yang terbesar diikuti oleh $3 ; 2 ; 5 ; 4 ; 6$ dan 7 , isolat non polar memiliki 4 spot yang terbesar adalah 3; 4; 2 dan 1 , isolat semipolar memiliki 4 spot $3 ; 2 ; 4$ dan 1 sedangkan isolat polar memiliki 7 spot yaitu $5 ; 4 ; 6 ; 7 ; 3 ; 2$ dan 1 (Gambar 3 dan Tabel 1).

Pada hasil tersebut terdapat harga Rf yang sama antara isolat nonpolar dan semipolar (spot 1 dan 2), kemungkinan terdapat 2 senyawa yang sama tapi tidak identik yang diperkuat oleh profil KLT baik di sinar tampak maupun disinar ultraviolet. Pada isolat polar terdapat satu senyawa yang sama dengan semipolar yang ditandai dengan 
harga Rf yang sama juga, maka perlu isolat tersebut dengan menggunakan GC-MS diperkuat lagi untuk mengetahui komponen tetapi hanya untuk senyawa yang volatile dan apa yang terdapat dalam tiap isolat dan termostabil.

senyawa yang sama terkandung didalam
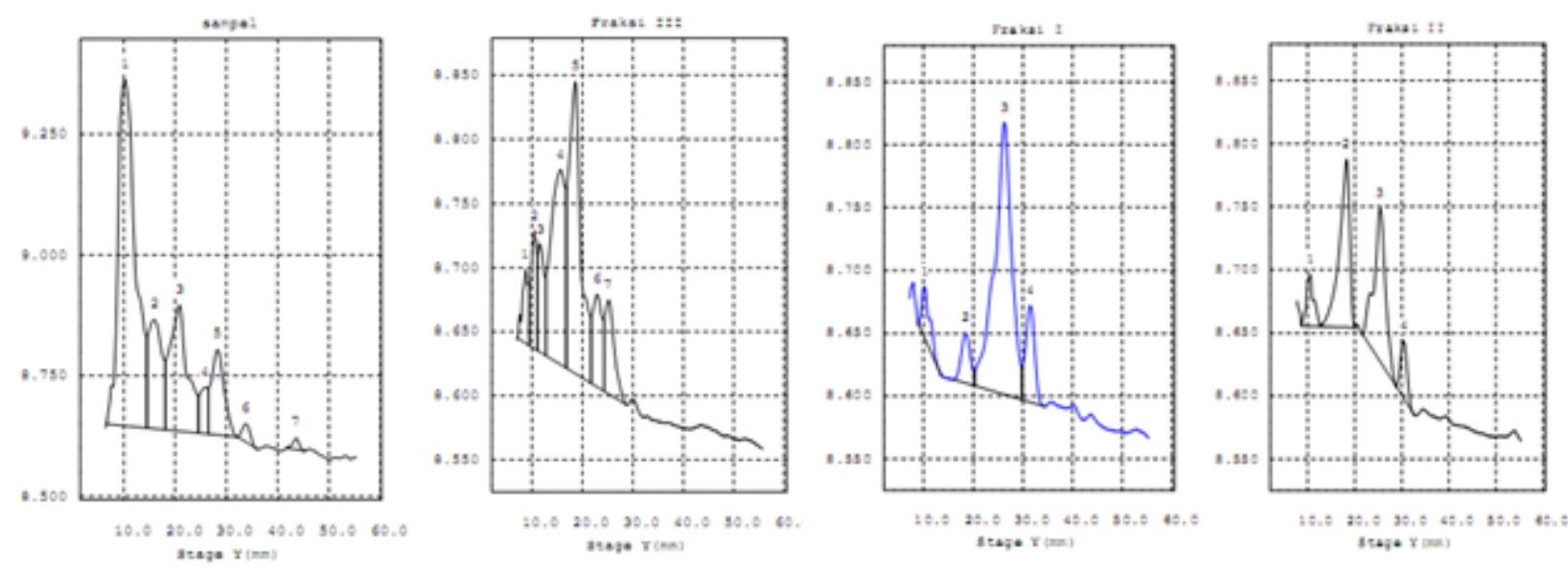

Gambar 3. Kromatogram ekstrak, isolat nonpolar, semipolar dan polar daun sirih dengan TLC Densitometer

Tabel 1. Data Luas Area dari KLT Densitometer

\begin{tabular}{rrrrr}
\hline $\mathbf{S}$ & \multicolumn{1}{c}{ Ekstrak } & \multicolumn{1}{c}{ Isolat nonpolar } & \multicolumn{1}{c}{ Isolat semipolar } & \multicolumn{1}{c}{ Isolat polar } \\
\hline $\mathbf{1}$ & $2826.736(10.19)$ & $77.505(10.16)$ & $73.269(10.51)$ & $79.914(8.80)$ \\
$\mathbf{2}$ & $701.257(15.95)$ & $83.471(18.48)$ & $335.417(18.26)$ & $122.036(10.59)$ \\
$\mathbf{3}$ & $1039.243(20.86)$ & $869.707(26.29)$ & $346.465(25.42)$ & $122.886(10.70)$ \\
$\mathbf{4}$ & $175.626(25.75)$ & $164.291(31.47)$ & $73.864(30.38)$ & $496.417(15.69)$ \\
$\mathbf{5}$ & $510.560(28.29)$ & - & - & $646.642(18.58)$ \\
$\mathbf{6}$ & $67.341(33.80)$ & - & - & $159.692(22.94)$ \\
$\mathbf{7}$ & $33.843(43.65)$ & - & - & $156.876(25.20)$ \\
\hline
\end{tabular}

3.5 Analisis Dengan Gas kromatografi gas dengan menggunakan Chromathography Massa Selective detektor massa selektif. Diperoleh data (GC MS)

Untuk mengetahui profil komponen berupa kromatogram yaitu isolat non polar, semipolar dan polar (Gambar 4).

senyawa tiap isolat digunakan metode 


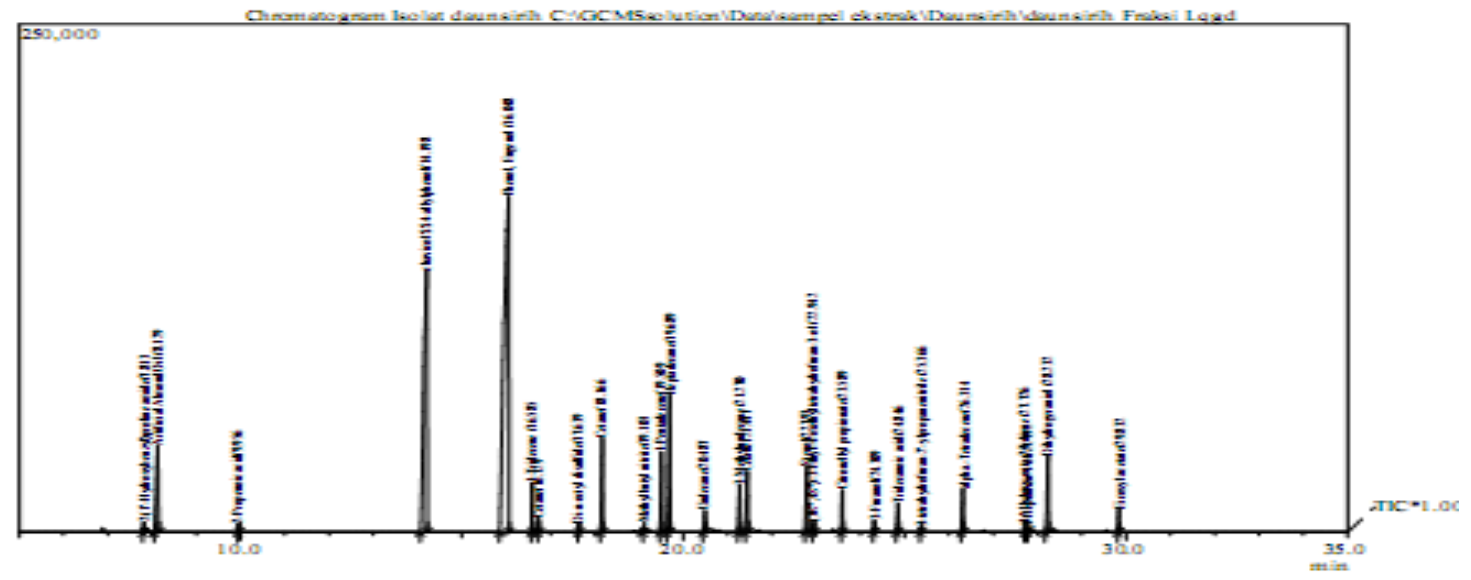

Gambar 4. Kromatogram isolat daun sirih

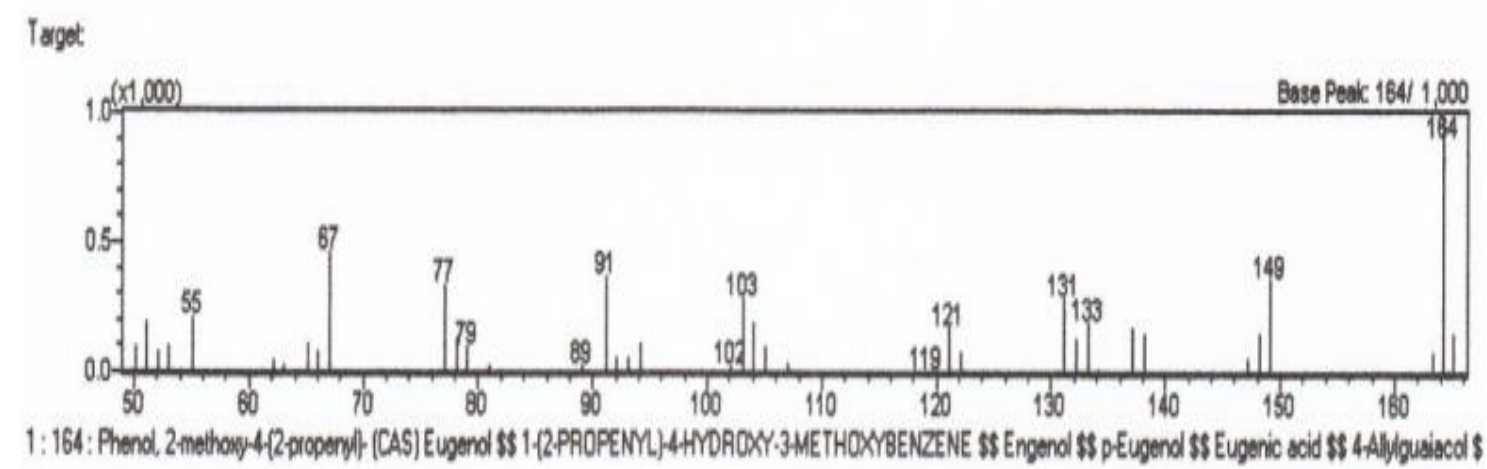

Gambar 5. Fragmentasi senyawa eugenol

Dari kromatogram diatas dapat dengan library (Wiley 7). Komponen mayor diinterpresentasikan bahwa tiap isolat banyak yang terkandung contohnya eugenol mengandung senyawa yang terkandung dari mempunyai pola fragmen (Gambar 5). pada menggunakan metode KLT preparative Spektrum massa memberikan puncak ion maupun densitometer, hasil yang diperoleh molekul $\mathrm{M}^{+} 164$ yang sekaligus merupakan hanya senyawa komponen mayor yang base peak. Pelepasan $\mathrm{CH}_{3}$ menghasilkan terkandung tiap isolat. Hasil tadi berupa pola fragmen $\left[\mathrm{C}_{9} \mathrm{H}_{9} \mathrm{O}_{2}\right]^{+}$dengan $\mathrm{m} / \mathrm{z} \quad 149$. fragmentasi dari tiap molekul massa yang Pelepasan $\mathrm{H}_{2} \mathrm{O}$ menghasilkan fragmen terionkan menjadi $\mathrm{mz}$ atau $\mathrm{m}^{(+)}$yang akan $\left[\mathrm{C}_{9} \mathrm{H}_{7} \mathrm{O}\right]^{+}$dengan $\mathrm{m} / \mathrm{z} 131$. Pelepasan atom $\mathrm{O}$ terfragmentasi menjadi molekul-molekul menghasilkan fragmen $\left[\mathrm{C}_{9} \mathrm{H}_{7}\right]^{+}$dengan $\mathrm{m} / \mathrm{z}$ yang lebih kecil berdasarkan kekuatan 115. elektronnya, fragmentasi tersebut dicocokkan 
Tabel 2. Penggolongan Senyawa Tiap Isolasi

\begin{tabular}{|c|c|c|c|c|c|}
\hline No & Golongan & Senyawa & F Non Polar & F Semi Polar & F Polar \\
\hline \multirow[t]{7}{*}{1} & Alkana & Tridekana & 0.60 & - & - \\
\hline & & Heksadekan & 2.70 & 1.49 & - \\
\hline & & Pentadekan & 1.31 & 2.18 & 10.03 \\
\hline & & Heptadekan & 2.65 & 1.57 & - \\
\hline & & Undekan & 1.33 & 0.21 & - \\
\hline & & Tetradekan & 0.84 & 0.72 & - \\
\hline & & Oktadekan & - & 1.60 & - \\
\hline \multirow[t]{2}{*}{2} & Alkohol & Stenol & 1.34 & 1.25 & - \\
\hline & & 2-butoksietanol & - & - & 2.73 \\
\hline \multirow[t]{2}{*}{3} & Aledehide & Benzaldehide & - & 0.53 & - \\
\hline & & Benzal-amonium klorida & - & 2.35 & - \\
\hline \multirow[t]{2}{*}{4} & Asam & Asam bensoat & 2.45 & - & 14.10 \\
\hline & Karboksilat & asam propanoat & 0.12 & - & - \\
\hline 5 & Benzopiren & 2.8 Chyrsendiol & - & - & 30.73 \\
\hline \multirow[t]{3}{*}{6} & Komponen & Kavikol & 11.00 & 10.73 & - \\
\hline & Fenol & Eugenol & 21.09 & 20.83 & - \\
\hline & & Cinnamommil klorida & - & 0.40 & 26.32 \\
\hline 7 & Furan & metil tetrahidrofuran & 0.16 & 0.26 & - \\
\hline \multirow[t]{2}{*}{8} & Organosulfur & Dioktil disulfide & - & - & 4.20 \\
\hline & Compound & & & & \\
\hline \multirow[t]{3}{*}{9} & Terpena & Citronella propionate & 0.68 & - & - \\
\hline & & Geraniol & 1.53 & - & - \\
\hline & & Cis-pinane & - & 0.64 & - \\
\hline
\end{tabular}

Dari penggolongan senyawa tersebut fenol; furan dan terpena, semipolar dapat dilihat tiap isolat mengandung mengandung alkana; aldehide; alkohol; golongan yang sama dan berbeda tiap satu komponen fenol; furan dan terpena sama lainnya. Isolat non polar mengandung sedangkan polar mengandung alkana; alkana; alkohol; asam karboksilat; komponen 
Identifikasi dan Isolasi Isolat....

alkohol; asam karboksilat; benzopiren;

komponen fenol dan sulfur (Tabel 2).

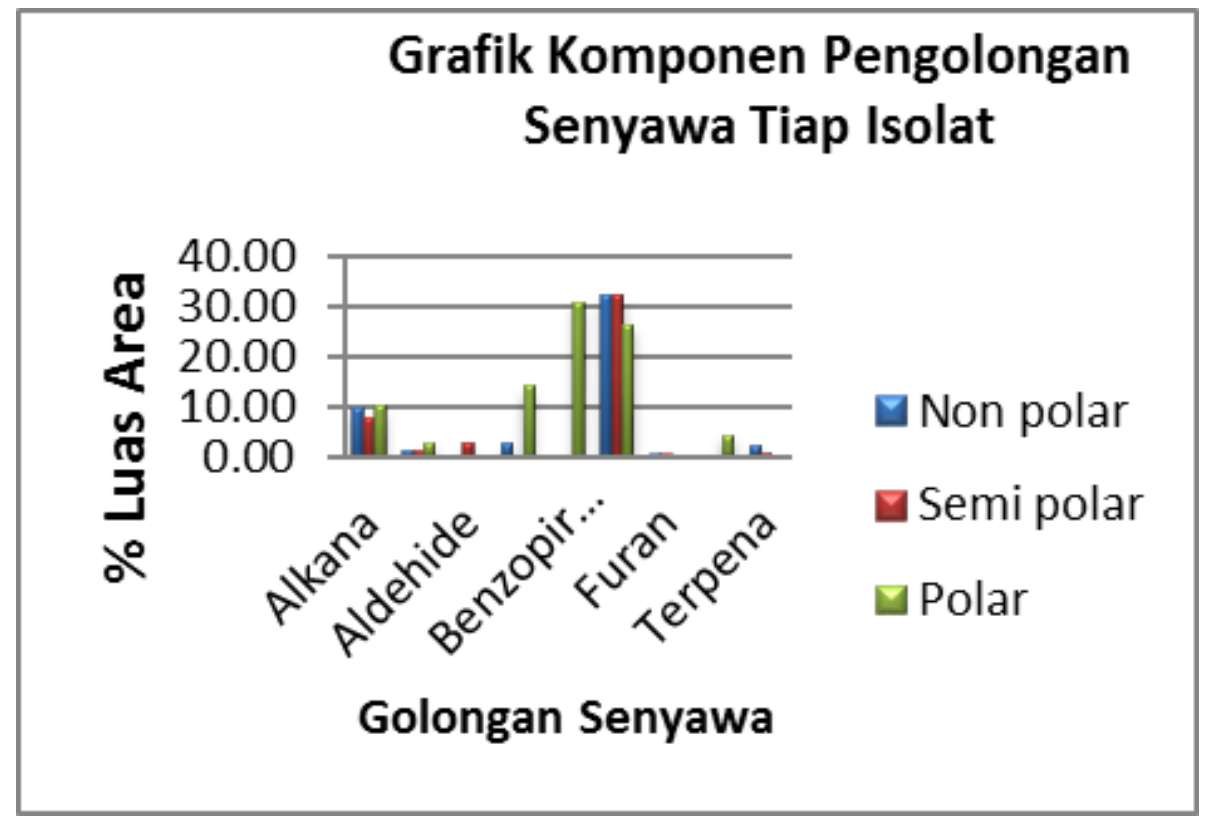

Gambar 6. Grafik Komponen Penggolongan Tiap Isolate

Tabel 3. Daftar \% Area Kandungan Tiap Golongan Isolat

\begin{tabular}{|lccccc|}
\hline Senyawa Isolat & Alkana & Alkohol & Aldehide & Karboksilat & Terpena \\
\hline Non polar & 9.43 & 1.34 & 0 & 2.57 & 0 \\
\hline Semi polar & 7.77 & 1.25 & 2.88 & 0 & 0 \\
\hline Polar & 10.03 & 2.73 & 0 & 14.1 & 30.73 \\
\hline & Benzopiren & Fenol & Furan & Organ & \\
& 32.09 & 0.16 & 0 & 2.21 & \\
\hline Non polar & 31.96 & 0.26 & 0 & 0.64 & \\
\hline Semi polar & 26.32 & 0 & 4.20 & 0 & \\
\hline Polar & & & & & \\
\hline
\end{tabular}

Identifikasi komponen senyawa yang terkandung dalam Isolat non polar, semi polar dan polar dalam fraksi semi polar ekstrak etanol daun sirih menggunakan metode GC MS diperoleh data golongan senyawa meliputi : Isolat nonpolar: Alkana $(9,43 \%)$; alkohol (1,34); asam karboksilat $(2,57)$; turunan fenol $(32,09)$; furan $(0,16)$ dan terpena $(2,21)$, Isolat semipolar: alkana (7,77); alkohol (1,25); aldehide (2,88); turunan fenol (31,96); furan $(0,26)$ dan terpena $(0,64)$ sedangkan isolat polar: alkana 
(10.03); alkohol (2,73); asam karboksilat $(14,10)$; benzopiren $(30,73)$; turunan fenol $(26,32)$ dan organosulfur $(4,20)$ dalam (Tabel $3)$.

Dari gambar grafik diatas semua isolat mempunyai komponen senyawa dari turunan fenol, alkohol dan alkana, tetapi konsentrasi area yang terbesar adalah golongan fenol diikuti alkana dan alkohol. Isolat non polar dan semi polar sama mempunyai senyawa golongan furan dan terpena, senyawa terpena yang terdapat pada isolat non polar lebih tinggi dari semipolar dan sebaliknya (Gambar $6)$.

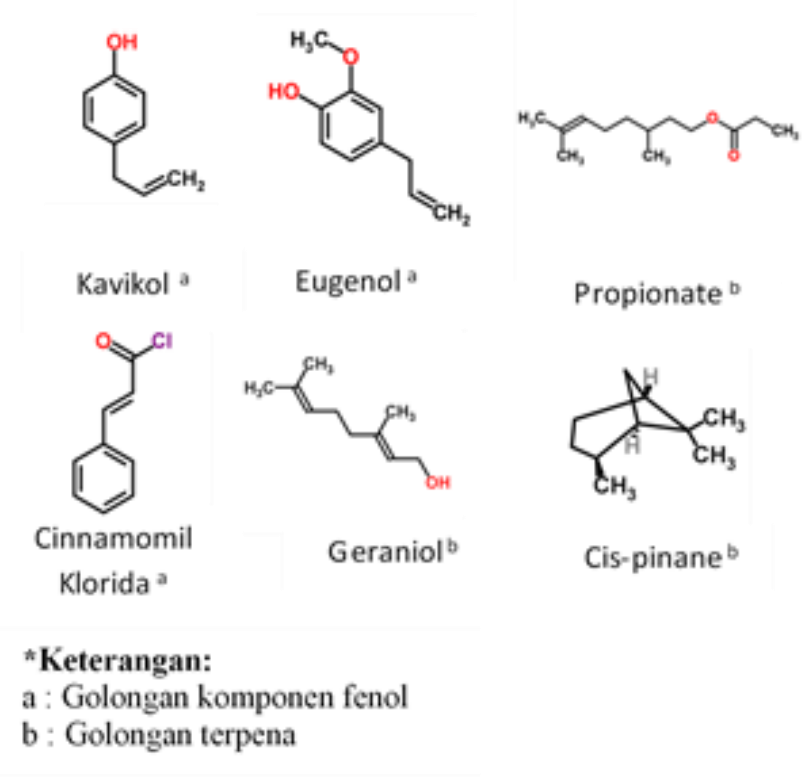

Gambar 7. Struktur Komponen Senyawa Fenol dan Terpena

Dari isolat tersebut terdapat senyawa komponen mayor yang mempunyai aktifitas sebagai antibakteri, kanker dan oksidan, diantaranya komponen fenol dan terpena. Isolat non polar dan semipolar mempunyai komponen fenol yang sama yaitu kavikol dan eugenol, senyawa tersebut mempunyai aktivitas sebagai antioksidant, bakteri dan kanker (Politeo et al, 2006). Senyawasenyawa terpena merupakan senyawa penanggung jawab sebagai anti oksidan diantaranya geraniol yang mempunyai gugus hidroksi bebas pada gugus isoprene (Gambar 7).
Pada isolat polar hanya mengandung komponen fenol cinamomil klorida yang berfungsi sebagai anti mikroba dan hipnotikasedatife (anandhhi V et al, 2011). Tiap - tiap isolat mempunyai komponen senyawa yang mempunyai aktivitas yang baik buat tubuh manusia.

\section{KESIMPULAN DAN SARAN}

\subsection{Kesimpulan}

1. Isolat fraksi non polar, semipolar dan polar mengandung senyawa komponen mayor yaitu golongan komponen fenol (kavikol, eugenol dan cinnamomil 
Identifikasi dan Isolasi Isolat....

klorida) dan terpena (geraniol, citronella propionate dan cis- pinane).

2. Isolat yang paling banyak mengandung komponen senyawa adalah non polar diikuti semipolar dan polar, dimana senyawa yang terbanyak adalah komponen fenol.

3. Komponen fenol dan terpena merupakan senyawa yang mempunyai aktivitas sebagai antimikroba, anti kanker dan anti radikal bebas.

\subsection{Saran}

Perlu dilakukan uji aktifitas terhadap isolat - isolat tersebut untuk mengetahui senyawa yang bertanggung jawab terhadap aktifitas dan hubungan korelasi tiap pengujian aktifitasnya.

\section{UCAPAN TERIMA KASIH}

Terima kasih disampaikan kepada Pimpinan dan Dosen Program Studi Farmasi Universitas Sahid Surakarta yang telah membantu penelitian ini dan kami ucapkan terima kasih juga disampaikan kepada staf Laboratorium Taksonomi Universitas Gadjah Mada Yogyakarta, yang telah mengidentifikasi tumbuhan.

\section{DAFTAR PUSTAKA}

Adams, R.P., 2001. Identification of Essential Oil Components by Gas Chromatography/Quadrupole Mass Spectroscopy. Allured, Illinois.

Aanandhi M. V., 2011, Synthesis, Antimicrobial and Sedative Hypnotic Activity of Cinnamoyl Ureas, International Journal of PharmTech Research, Vol. 3, No.1, pp 99-103.
Arambewela L, Kumaratunga K.G.A, Dias K., 2005, Studies on Piper betle of Sri Lanka, J.Natn. Sci. Fondation Sri Lanka 33 (2): 133-139.

Haryoto, 2007, Antioksidan dari Fraksi Polar Ekstrak Metanol dari Kulit Kayu Batang Shorea accuminatissima dengan Metode DPPH, Jurnal Ilmu Dasar, FMIPA UNEJ, Vol. 2, No.3: 185-195.

Parmar V.S, Jain S.C, and Bisht K.S et al., 1997, Phytocemistry of genus Piper, Phytochemistry I 46 (4): 597-673.

Parwata A.O.M, Susanah W. R, dan Yoga R., 2009, Isolasi Dan Uji Antiradikal Bebas Minyak Atsiri Pada Daun Sirih (Piper betlle Linn) Secara Spektrofokospi Ultra Violet-Tampak, Jurnal Kimia 3 (1), FMIPA Udayana, Januari 2009 : 7-13.

Politeo O, Jukic M, Milos M., 2007, Chemical composition and antioxidant capacity of free volatile aglycones from basil (Ocimum basilicum L.) compared with its essential oil, Food Chemistry 101 Elsavier, 10.1016/j.foodchem.2006.01.045.

Sastroamidjojo, S. 1997. Obat Asli Indonesia, Dian Rakyat, Jakarta.

Stenhagen, E., Abrahamson, S., MacLafferty, F.W., 1974. Registry of Mass Spectral Data. J. Wiley \& Sons, New York. 
Ahwan, JIF Farmasyifa, 1(2): 88 - 98 